\title{
Attitude of staff nurses towards the use of physical restraints on patients
}

\author{
Abstract \\ Background: Nurses' attitude and practice play an important role in the healthcare \\ settings as they are closely involved in caring for restrained patients. The attitude \\ of nurses toward restraints is considered as one of the main reasons for variations in \\ their use. \\ Objectives of the study: \\ i. To assess the attitude of nurses towards the use of physical restraints on patients. \\ ii. To determine the association between attitude towards use of physical restraints \\ on patients and selected baseline variables of staff nurses.
}

Volume 5 Issue 6 - 2018

\author{
Jose AE, Mendonsa V, Mylliem B, Thomas S \\ Father Muller College of Nursing, India
}

Correspondence: Agnes Elizabeth Jose, Professor, Department of Mental Health Nursing, Father Muller College of Nursing, Mangalore, India, Tel +9l 805015783।,

Email agnasej201 I@fathermuller.in

Received: October 16,2018 | Published: November 22, 2018

Methods: A cross sectional, descriptive design was used to assess the attitude of nurses towards the use of physical restraints on patients. The study was conducted among 90 staff nurses, selected by purposive sampling technique. Data collection was done at a Medical College Hospital, Mangaluru, India using Attitude towards the Use of Physical Restraint Scale.

Results: The results revealed that $76.6 \%$ staff nurses were having favorable attitude and $23.3 \%$ staff nurses were having unfavorable attitude towards the use of physical restraints. The mean attitude score was $55.05( \pm 7.45)$. There was an association between attitude of staff nurses towards the use of physical restraints on patients and present area of their working $\left(\mathrm{x}^{2}=0.026\right)$. More favorable attitude towards the use of physical restraint was found among the staff nurses working in psychiatric and private wards.

Conclusion: The study revealed that majority of the staff nurses were having favorable attitude towards the use of physical restraint on patients.

Keywords: attitude, nurses, physical restraints, patients

\section{Introduction}

The use of physical restraints has been a controversial, yet frequently used as nursing intervention for confused and hospitalized frail elderly and patients with severe mental disorders over the past two decades. ${ }^{1}$ The use of physical restraints is a very common practice in various clinical settings i.e. ICU, medical-surgical, psychiatric and pediatric units. Their use in hospital is often considered to be an accepted and perhaps unquestioned practice related to patient safety. ${ }^{2}$

A physical restraint is any manual method or physical or mechanical device, material or equipment attached or adjacent to the patient's body that he or she cannot easily remove, that restricts freedom of movement or normal access to one's body. ${ }^{3}$ The most commonly used restraints are vests, straps/belts, limb ties, wheel chair bars and breaks, mummy restraint, bed side rails and water mattress. ${ }^{4}$ The use of restraint is a major infringement on a person's civil liberty and should only be an option of last report. Restraint is to be used when all alternative options have been explored and have failed or are considered inappropriate. The primary purpose of restraint should always be the promotion and safety. The protection of others may also be a consideration. Restraint should be used as part of a holistic intervention plan. This plan should be developed and approved by the treating team in consultation with the person and their family and with the consent of a guardian or enduring guardian.
Restraint should not be used for staff convenience or to overcome lack of adequate staff support and supervision. ${ }^{5}$ Restraints should be used only for the safety of the patients or others. It prevents harm to self and others in situations, such as attempts to get out of bed or a chair unassisted although instructed to ask for assistance, or attempts to remove medically necessary intravenous lines or medical tubes. It promotes personal safety of the patient when there is evidence of restlessness, poor judgment, combativeness, agitation, disorientation, unsteady gait or movement, morbidity or mortality risks associated with physical restraints. ${ }^{1}$

A study conducted among the nursing staff reported that they have no emotional reaction and many reported automatic responding during restraint event in which they did not feel any emotion. This lack of feelings among nurses might be due to the fact that the practice had become so ritualized that it does not provoke any reaction. ${ }^{6}$ Another study conducted among pediatric nurses reported that nurse's shortages were the main reason for increased physical restraint applications. $71.1 \%$ of them indicated that no need of written orders for physical restraint use. ${ }^{7}$ The study conducted among nurses in two psycho-geriatric wards of one of the mental hospitals in Hong Kong demonstrated only a moderate level of knowledge of restraint use and slightly negative attitudes toward this practice, and psychological reactions towards restraint use. ${ }^{8}$ There is still an ongoing debate concerning whether or not to use physical restraint with confused or 
frail older patients in various elderly care settings. Nurses' views and attitudes towards the use of physical restraints in controlling patients' behavior and ensuring patient safety may create conflicts with patients' rights, including their autonomy in making decision for their own care. ${ }^{9}$ Attitude towards the use of physical restraints is influenced by lack of staff support and supervision, inadequate knowledge of restraint policy, inappropriate use of restraints, shortage of staff nurses and lack of restraint policy in some hospitals.

\section{Methods}

A descriptive research design was used in this study. Ethical clearance was obtained from the Institutional Ethics Committee. A formal written permission was obtained from the concerned authorities to conduct research study in the hospital. The study was conducted among the nurses working in ICCU, MICU, PICU, SICU, medical-surgical, pediatric, post-operative and psychiatric settings. Ninety staff nurses who have been working in any of those wards for the last 3 months were selected by purposive sampling. Attitude towards the Use of Physical Restraints Scale was used to determine the attitude towards physical restraints which has 20 items. The tool was prepared after extensive review of literature and discussion with the experts. The tool was validated by five experts. Each positively stated item was scored 5 (Strongly agree), 4 (Agree), 3 (Uncertain), 2 (Disagree) and 1 (Strongly disagree) and negatively stated items were scored reversely. The total score of the tool was 100 . Those who scored $\leq 50$ were considered to have unfavorable attitude and who scored $>50$ was considered to have favorable attitude. The reliability of the attitude scale was tested using split half method to establish internal consistency. Karl Pearson's correlation co-efficient formula was used to find out the reliability. The reliability of the tool was 0.8 which indicated that the tool was reliable. The pilot study was conducted among 10 staff nurses and the study was found to be feasible.

During the data collection, the investigators gave assurance regarding the confidentiality of information. An informed written consent was obtained from the respondents indicating their willingness to participate in the study. Baseline proforma and Attitude towards the Use of Physical Restraint Scale were administered to the staff nurses. About 10-15minutes were taken by each subject for the completion of tool.

Statistical analysis: Data was analyzed using SPSS version 16. The tests used were frequency, percentage, mean, median, standard deviation, mean percentage, chi-square and fisher's exact test.

\section{Results and discussion}

\section{Baseline characteristics of staff nurses}

In the present study, majority $(86.7 \%)$ of subjects were under the age group of 20-30years. The mean age of staff nurses was 25.32years $(\mathrm{SD}=4.09)$. Majority (88.9\%) were females. Majority $(87.8 \%)$ of the subjects were Christians. Maximum subjects (58.9\%) participated in the study completed B Sc(N), 24.4\% GNM and 16.7\% PB B Sc (N). Among the participants $78.9 \%$ were unmarried. Majority (97.8\%) of the subjects were staff nurses and $2.2 \%$ were ward in-charges. Most of the staff nurses $(45.6 \%)$ who participated in the study were having working experience between 1 -3years, $34.4 \%$ were <1year, $10 \%$ were between 3-6years and 10\% were above 6 years of experience. The working area of staff nurses was as follows: in medical wards $12.2 \%$; surgical wards 13.4\%; ICCU/MICU/SICU/ PICU 22.2\%; pediatric $7.8 \%$; psychiatric wards $17.8 \%$ and $25.6 \%$ in private wards. More than half of the subjects $(55.6 \%)$ participated in the study were having a work experience of $<1$ year, $35.6 \%$ were between 1-3years,
$5.6 \%$ were between $3-6 y e a r s$ and $3.3 \%$ were above 6 ears. The mean years of experience was 2.33 years $(\mathrm{SD}=3.08)$. The mean duration of working in the present area was $1.66 \mathrm{yrs}(\mathrm{SD}=1.33)$. A study which was conducted to assess the patients' perspectives on and nurses' attitude towards the use of restraints/seclusion in a Turkish population showed the consistent findings to the gender, where majority of the staff nurses were females $(64.1 \%)$ and the duration of working of the staff nurses (59.4\%) were between $0-5$ years. ${ }^{10}$

Another study conducted to assess the use of physical restraints in intensive care units (ICUs) at Ain Shams University Hospitals showed the consistent findings to both the female gender (90\%) and as well as to the age group (76.4\%) which were between 20 and 35years of the present study, whereas professional qualification for most of the nurses $(49.1 \%)$ were diploma nursing which was inconsistent with the present study. ${ }^{11}$ Another study which was conducted to assess the nurses' attitudes towards using of patients' physical restraint at psychiatric hospital in Baghdad showed the inconsistent findings to this present study. The results revealed that the majority (53.3\%) were under the age group of 30-39 years. Most of the staff nurses (72.4\%) were males and $41.9 \%$ graduated from the medical institution. ${ }^{12}$

\section{Attitude of staff nurses towards physical restraints}

Table 1 reveals that $76.6 \%$ staff nurses were having favorable attitude and $23.3 \%$ staff nurses were having unfavorable attitude towards the use of physical restraints on patients. A study which was conducted to assess the patients' perspectives on and nurses' attitude towards the use of restraints/seclusion in a Turkish population showed the inconsistent findings to the present study. Many nurses (65.6\%) stated that they were upset when they restrained or decided to restrain a patient, $62.5 \%$ of nurses regarded the patients' aggressive behavior as the cause of the restraint/seclusion, $82.8 \%$ of the nurses did not want restraint/seclusion prohibited. ${ }^{10}$

Table I Distribution of subjects according to the attitude $n=90$

\begin{tabular}{lllll}
\hline Grading & $\begin{array}{l}\text { Percentage } \\
\text { (\%) }\end{array}$ & $\begin{array}{l}\text { Range of } \\
\text { score }\end{array}$ & $\begin{array}{l}\text { Frequency } \\
\text { (f) }\end{array}$ & $\begin{array}{l}\text { Percentage } \\
\text { (\%) }\end{array}$ \\
\hline Favourable & $>50$ & $51-100$ & 69 & 76.6 \\
Unfavourable & $\leq 50$ & $20-50$ & 21 & 23.3 \\
\hline
\end{tabular}

Maximum score $=100$

A comparative study was conducted on comparisons of restraint use in nursing homes in eight countries (Denmark, France, Iceland, Italy, Spain, Sweden, and the USA) showed that In all countries, there is a constant increase in use of restraints with increasing activities of daily living difficulties and cognitive dysfunction. ${ }^{13}$

Table 2 shows that the mean attitude score was $55.05( \pm 7.45)$ towards the use of physical restraints on patients which showed a positive attitude towards the use of restraints. However, the mean score was not high. In a study conducted with 64 nurses, the majority of nurses reported that restraint is a valuable intervention method, and needs to continue to be used. Nurses argued that the restraint/seclusion is necessary, not punitive and this procedure is effective for the patients to feel better and calm. ${ }^{14}$ In another study conducted among nurses, it has been argued that the patients would be more insecure and dangerous without restraining. ${ }^{15}$ Another study conducted to assess the use of physical restraints in intensive care units (ICUs) at Ain Shams University hospitals showed inconsistent findings to this study. The attitude scores of the respondent nurses ranged from 17 to 30 (median: $23)$. The majority $(97,88 \%)$ of them disagreed with the statements that 'the hospital is legally responsible to use restraint to keep the 
patient safe'. ${ }^{11}$ A descriptive study conducted to assess physical restraint use among hospitalized elderly Thais showed inconsistent findings to the current study. A significant difference was found between the family members' and nurses' attitude towards physical restraint use. The mean score on attitude towards physical restraint use of family members of restrained elderly patient $(46.9 \pm 3.4)$ was more favorable than that of the nurses $(44.6 \pm 3.9)$ who restrained elderly patient. ${ }^{16}$ Although restraint/seclusion has many negative physical and psychological effects in patients and nurses, it continues to be a part of daily psychiatric and other hospital settings practice. It is important to inform the patient, apply the restraint as briefly as possible, check on the patient at specified interval, meet his/her physical needs during restraints. The nurses need to plan and intervene the care according to the need of the patients and get feedback after restrained. ${ }^{10}$

Table 2 Mean and standard deviation of attitude scores $n=90$

\begin{tabular}{lll}
\hline Variable & Mean & Standard deviation \\
\hline Attitude & 55.05 & 7.45
\end{tabular}

Maximum score $=100$

Restraint is still an argumentative issue that nursing deals almost daily in their practice. Although the main aim of restraint is to prevent harm either to the patient him/her self, or to others, it is still causing a major physical, and psychological harm and impact on the patients such as skin irritation and damage, risk for respiratory distress, strangulation, loss of autonomy and freedom in making decisions, and loss of self-esteem. Moreover, nurses should never apply restraint as a punishment or even threaten the patient by restraining if he/she doesn't comply with the treatment regimen, because simply this can be held against the nurses as an assault, battery, and false imprisonment, which in turn is a legal issue that can lead to negative consequences on the nurses themselves. Whenever its necessary family should be engaged in the decision planning and making. Furthermore consent must be obtained, and complete well documented physician order should be written, which emphasize on the importance of strict observation of restrained patients. The hospitals should formulate appropriate restraint policies and should monitor continuously. The nursing educators should help the students to update their knowledge regarding the use of physical restraint safely and appropriately on patients. The nurses in clinical setting should explore effective alternative interventions instead of considering restraining clients as first option. If physical restraint is to be employed, it should be used properly. Staff must understand not only how to use it properly, but also need to know its negative consequences so as to limit the frequency with which it is used. Nurse administrators should take keen interest in formulating policies regarding the safe use of physical restraints whenever necessary for the better quality nursing care.

\section{Association of attitude towards use of physical restraints on patients with selected baseline variables of staff nurses}

There was an association between attitude of staff nurses towards the use of physical restraints on patients and the present area of their working $\left(x^{2}=0.026\right)$. The more favorable attitude towards the use of physical restraints was found among the staff nurses working in psychiatric and private wards. Some reasons for the favorable attitude can be patients' aggressiveness, lack of experience and communication skills. In the study conducted on nurses' attitudes towards using of patients' physical restraint at psychiatric hospitals in Baghdad showed that there is no significant relationship between nurses' attitudes and any of their characteristics. ${ }^{12}$

\section{Conclusion}

The findings of the study suggest the need to provide in-service education program on physical restraint use in various care settings to improve the knowledge and develop right attitudes. A policy on the use of restraints should be developed to guide health care practitioners in the management of patients where restraint cannot be avoided.

\section{Acknowledgments}

The authors are thankful to management for granting the permission to conduct the study in the hospital setting.

\section{Conflicts of interest}

Authors declare that there is no conflict of interest.

\section{References}

1. Bryant H, Fernald L. Nursing knowledge and use of restraint alternatives: acute/chronic care. Geriatric Nursing. 1997;18(2):57-60.

2. Minnick AF, Mion LC, Leipzig R, et al. Prevalence and patterns of physical restraint use in the acute care settings. J Nurs Adm. 1998;28(11):19-24.

3. Use of restraints and safety devices.

4. Akansel N. Physical restraint practices among ICU nurses in one university hospital in Western Turkey. Health Sci J. 2007;1:4.

5. Position statement: Restraints. Office of the Public advocate, Department of Attorney General, Government of Western Australia.

6. Sequeira H, Halstead S. Psychological effect on nursing staff of administering physical restraint in a secure psychiatric hospital: When I Go Home, It's Then That I Think About It. The Brit J of Forensic Pract. 2004;6(1);3-15

7. Demir A. The use of physical restraints on children: Practices and attitudes of pediatric nurses in Turkey. Int Nurs Rev. 2007;54(4):367-374

8. Chien W, Lee I. Psychiatric nurses knowledge and attitudes toward the use of physical restraint on older patients in psychiatric wards. Int $J$ Multiple Res Approaches. 2007;1(1):52-71.

9. Haber LC, Fagan-Pryor EC and Allen M. Comparison of registered nurses/'nursing assistants' choices of intervention for aggressive behaviours. Issues in Mental Health Nursing. 1997;18(2):113-124.

10. Ayse O, Emine Y, Funda K. Patients' Perspectives on and Nurses Attitude towards the Use of Restraints/Seclusion in a Turkish Population. Int J of Caring Sci. 2016;9(3):932-938.

11. Sonya MS, Azab Lobna, Abu Negm. Use of Physical Restraints in Intensive Care Units (ICUs) at Ain Shams University Hospitals, Cairo. J Am Sci. 2013;9(4):230-240.

12. Mohammed QQ. Nurses Attitudes towards Using of Patients' Physical Restraints at Psychiatric Hospitals in Baghdad. Kufa J for Nurs Sci .2015;5(3):105-112.

13. Ljunggren G, Phillips CD, Sgadari A. Comparisons of restraint use in nursing homes in eight countries. Age and Ageing. 1997;26(2):43-47.

14. Alty A. Nurses learning experience and expressed opinions regarding seclusion practice within one NHS trust. $J$ of Adv Nurs. 1997;25(4):789-793.

15. Petti TA, Mohr WK, Somers JW. Perceptions of department: nurses contend with prevention in the healthcare arena. Nurs Clin North Am. 2001;14(3):115-127.

16. Busara Oearsakul, Yupapin Sirapo-ngam, Neville E Strumpf, et al Physical Restraint Use among Hospitalized Elderly Thais. Pacific Rim Int J Nurs Res. 2011;15(2):125-136. 